\title{
Walras Competition Model, an Example of Global Optimization
}

\author{
Jonas MOCKUS \\ Kaunas Technological University, Vilnius Technical University, \\ Institute of Mathematics and Informatics, \\ Akademijos 4, 08663 Vilnius, Lithuania \\ e-mail:mockus@soften.ktu.lt
}

Received: September 2004

\begin{abstract}
Walras theory is well known and widely used in models of market economy. Various iterative methods are developed to search for the equilibrium conditions.

In this paper a new approach is proposed and implemented where the search for Walras equilibrium is defined as a stochastic global optimization problem. This way random nature of customer arrivals is represented and the convergence to equilibrium is provided if equilibrium exists.

This paper describes a part of a Web-based integrated system for scientific cooperation and distance graduate studies of theories of optimization, games and markets which aim is to provide researchers and graduate students with hands-on experience on effective use of software. The objectives are to provide a tool for scientific collaboration and to stimulate creative abilities of graduate students to work as independent researchers. The web-site http://soften.ktu.lt/ mockus includes a family of economic and finnacial models regarding them all as examples of the the general optimization theory.
\end{abstract}

Key words: Walras model, Nash equilibrium, stochastic global optimization, internet environment.

\section{Introduction}

Future enterprises will be characterized by a focus on total quality, globalization, an object-oriented approach, and a business process-oriented approach. The globalization will lead to the "Virtual Enterprise". The virtual enterprise can obtain a competitive position by defining and re-engineering its business processes. However, such re-engineering requires an enterprise model.

A well known example is the Factory of the Future (FOF) project (Rolstadas, 1995). It is based on a generalization of the Walras model, and defines a number of design choices and performance indicators.

There are well known and widely used iterative algorithms to define equilibrium in Walras models under some conditions (Scarf and Hansen, 1973; Herings, 1994). In this paper we consider the search for the Nash equilibrium (Nash, 1950) of the Walras model of the theory of games and markets (Rosenmuller, 1981) under different non-traditional conditions. The main difference is stochastic customer arrivals and stochastic service 
times. This is important considering "markets" represented by a collection of small number of independent servers.

Each server tries to maximize the profit by setting optimal prices for services and resources. The resources define the service rate ${ }^{1}$.

First, an agreement about prices of services and resources - the "Contract Vector" (CV) - is made. Then profits of individual servers are maximized by changing individual prices under the assumption that all their partners respect the prices set by CV. This way one transforms the Contract-Vector into the "Fraud-Vector" $(\mathrm{FV})^{2}$.

The optimization problem is to search for such CV that minimizes the deviation of the Fraud-Vector from the Contract-Vector. This makes the fraud less relevant. The fraud is irrelevant and the Nash equilibrium is achieved, if the deviation is zero. Then servers cannot increase their profits by changing service and resource prices defined by the contract.

For simplicity the quality of service is defined as the average time lost by customers while waiting for services ${ }^{3}$. A customer prefers the server with lesser total service cost. The total cost is defined as the service price plus estimated waiting losses (expressed in the same money as the service price). A customer goes away, if the total cost exceeds certain critical level. A flow of customers is stochastic. Service times are stochastic, too. There is no known analytical solution for this model. The results are obtained by MonteCarlo simulation.

It is supposed that the server capacity depends on several resources. Each server owns a minimal amount of all resources for its own needs. It is assumed that each server allocates a fixed amount of single resource for sale. Thus, the number of different resources in the "market" is equal to the number of servers. The distribution of the market resources are controlled by their prices ${ }^{4}$.

In the model, the servers share each other resources. Therefore, we are looking for the equilibrium of both the prices for services and the prices for shared resources.

This market model illustrates the possibilities and limitations of the optimization theory and numerical techniques in models of competitive environments. Initially the model was developed as a test function for the Bayesian algorithms of stochastic global optimization (Mockus, 2000). However, this simple model may help to design more realistic ones. Simple models help to understand processes of competition better. In addition it shows the relation between the optimization and equilibrium. This is important for studies of the Operations Research and the Theory of Games and Markets.

The model is implemented as an Java applet on the web-site:

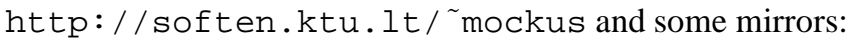

http://eta.ktl.mii.lt/ mockus,

http://optimum2.mil.1t/ jonas2,

http://mockus.us/optimum.

\footnotetext{
${ }^{1}$ The average number of customers that would be served in nonstop operations, we consider this rate as the server capacity.

${ }^{2}$ Often FV is called as the "Best Response", however we think that the name "Fraud Vector" describes the situation better because that is not necessarily the best response.

${ }^{3}$ Expected waiting time is just one of many parameters defining the quality of services. This parameter is easy to estimate and important in some cases, for example in the network servers and crowded supermarkets.

${ }^{4}$ This model is similar, but not identical, to the traditional Walras model (Walras, 1874).
} 
That means that anybody can test the presented examples and some new ones, too. Thus the scientific cooperation is natural and easy. In this sense the models implemented as Java applets are similar the analytical ones. The difficulties of development are similar, too. The first version was implemented by (Perlibakas, 1999), the Profit Analysis using the Wiener filter was improved by (Sviderskaite, 2003), the updated version was a part of Master thesis by (Skruodys, 2004). The final version is the result of long process of coding and testing by (Treigys, 2003; Treigys, 2004).

The software implementation of the Walras model is specific and very important problem. The main theoretical and practical difficulty is to balance the accuracy and efficiency. Some aspects of this problem are discussed in this paper. The complete description will by published as a separate paper by the software author Povilas Treigys (Treigys, 2004).

\section{Profit Functions}

Let us consider $m$ servers providing the same service. In the Walras model, the capacity $w_{i}$ of servers $i=1, \ldots, m$ depends on the resource vector $x_{i}+g_{i}=\left(x_{i j}+g_{i j}\right), i, j=$ $1, \ldots, m)$ defining the consumption of different resources. Each server $i$ may sale a single resource up to a limit $b_{i}$ charging $p_{i}$ for a unit of this resource to partner-servers. Therefore:

$$
b_{i}=\sum_{j=1, \ldots, m} x_{i j}, \quad i=1, \ldots, m .
$$

The server $i$ controls the vector $x_{i}=x_{i j}, j=1, \ldots, m$. The component $x_{i j}$ denotes the amount of resource $b_{j}$ used by the server $i$. The server $i$ also controls the price $y_{i}$ for services. and the price $p_{i}$ that is charged for resource $p_{i}$.

Assume that the server capacity $w_{i}$ is an increasing function of the resources.

$$
w_{i}=\phi_{i}\left(x_{i}+g_{i}\right)
$$

A simple example of this function

$$
w_{i}=k_{i} \prod_{j=1}^{m}\left(1-\exp \left(-k_{i j}\left(x_{i j}+g_{i j}\right)\right)\right) .
$$

The resource component $x_{i j}+g_{i j}$ denotes the total amount of resource $j$ used by server $i$ including both the "market" resource $x_{i j}$ and the "local" resource $g_{i j}$. The coefficient $k_{i j}$ shows how useful is the resource $b_{j}$ for the server $i$. The coefficient $k_{i}$ defines the capacity limit when $x_{i j} \rightarrow \infty$.

The profit of the $i$ th server:

$$
u_{i}=u_{i}\left(x_{j}, y_{j}, p_{j}, j=1, \ldots, m\right)=a_{i} y_{i}+p_{i} \sum_{j \neq i} x_{i j}-\sum_{j \neq i} p_{j} x_{i j} .
$$


Here $i$ is the server index. $a_{i}$ is the rate of customers. $y_{i}$ is the service price. $x_{j}=$ $\left(x_{j k}, k=1, \ldots, m\right)$ is the resource vector determining the capacity $w_{j}$ of server $j$.

The rate of customers $a_{i}$ of each server $i$ is defined by the total service cost

$$
c_{i}=y_{i}+\gamma_{i}
$$

where $\gamma_{i}$ is waiting $\operatorname{cost}^{5}$ at the server $i$. A customer goes to the server $i$, if

$$
c_{i}<c_{j}, \quad j=1, \ldots, m, j \neq i, c_{i} \leqslant c_{0} .
$$

A customer goes away, if

$$
\min _{i} c_{i}>c_{0}
$$

where $c_{0}$ is the critical cost. The rate $a$ of incoming consumers flow is fixed:

$$
a=\sum_{i=0}^{m} a_{i}
$$

where $a_{0}$ is the rate of lost customers.

From the balance condition follows $x_{i i}=b_{i}-\sum_{j \neq i} x_{j i}$. Note that the profit $u_{i}$ of each individual server $i$ depends on the parameters $x_{j}, y_{j}, p_{j}$ of all $m$ servers $j=1, \ldots, m$.

Here the first component $a_{i} y_{i}$ defines the income of a server $i$ collected from customers of for its services. The second component $p_{i} \sum_{j \neq i} x_{i j}$ defines the sum received from other servers for the resource $b_{i}$. The third component $\sum_{j \neq i} p_{j} x_{i j}$ shows the expenses for resources obtained from other servers.

In two-server cases

$$
u_{1}=u_{1}\left(x_{12}, y_{1}, p_{1}, x_{21}, y_{2}, p_{2}\right)=a_{1} y_{1}+p_{1} x_{21}-p_{2} x_{12},
$$

and

$$
u_{2}=u_{2}\left(x_{21}, y_{2}, p_{2}, x_{12}, y_{1}, p_{1}\right)=a_{2} y_{2}+p_{2} x_{12}-p_{1} x_{21} .
$$

Here $x_{11}$ and $x_{22}$ are not included explicitly because they are defined by the balance conditions

$$
x_{11}=b_{1}-x_{21}, x_{22}=b_{2}-x_{12} .
$$

By fixing the lower and upper limits $a_{p_{i}}, a_{x_{i j}}, a_{y_{i}}, b_{p_{i}}, b_{x_{i j}}, b_{y_{i}} i, j=1, \ldots m$ we obtain the inequalities

$$
\begin{aligned}
& a_{p_{i}} \leqslant p_{i} \leqslant b_{p_{i}}, \quad a_{x_{i j}} \leqslant x_{i j} \leqslant b_{x_{i j}}, \\
& a_{y_{i}} \leqslant y_{i} \leqslant b_{y_{i}}, \quad i, j=1, \ldots, m .
\end{aligned}
$$

\footnotetext{
${ }^{5}$ It is. assumed for simplicity that the waiting cost is equal to an average waiting time.
} 
Conditions (6) and (7) separate the flow of incoming customers into $m+1$ flows. This makes the problem very difficult for analytical solution. The separated flow is not simple one, even in the case when the incoming flow is Poisson (Gnedenko and Kovalenko, 1987). Thus, we need the Monte Carlo simulation, to define average rates of customers $a_{i}, i=0,1, \ldots, m$, by conditions (6) (7), and average profits $u_{i}, i=1, \ldots, m$ by expression (59).

\section{Nash Equilibrium}

Denote by $z=\left(z_{i}, i=1, \ldots, m\right)$ the vector of parameters that servers $i$ include into the contract. First we fix some initial values of contract vector $(\mathrm{CV})^{6} z^{0}=\left(z_{i}^{0}, i=1, \ldots, m\right)$. Then the values of the corresponding fraud vector $(\mathrm{FV}) z^{1}=\left(z_{i}^{1}, i=1, \ldots, m\right)$, are obtained maximizing profits of each server $i$ separately. The maximization is performed under the assumption that other partners $j \neq i$ honor the contract $\left(z_{j}^{0}, j=1, \ldots, m\right.$, $j \neq i)$

$$
z_{i}^{1}=\arg \max _{z_{i}} u_{i}\left(z_{i}, z_{j}^{0}, j=1, \ldots, m, j \neq i\right), \quad i=1, \ldots, m .
$$

Formally, condition (13) transforms the vector $z^{n}=\left(z_{i}^{n}, i=1, \ldots, m\right), n=0,1,2, \ldots$ into the vector $z^{n+1}$. To make expressions shorter denote this transformation by $T$

$$
z^{n+1}=T\left(z^{n}\right), \quad n=0,1,2, \ldots
$$

The equilibrium is at the fixed point $z^{n}$, where

$$
z^{n}=T\left(z^{n}\right)
$$

The fixed point $z^{n}$ exists, if both the feasible set $B$ and all the profit functions are convex (Michael, 1976). Traditional way to reach the equilibrium is by iterations (14). That is possible if the transformation $T$ is contracting (von Neumann and Morgenstern, 1953). Othervise minimization of the deviation from equilibrium is needed. This is not a simple task considering stochastic arrivals and service times. The problem is very difficult if the deviation is not only stochastic but multimodal, too ${ }^{7}$.

\section{Existence of Nash Equilibrium}

The first existence theorem is due to Nash (Nash, 1951) and dates back to 1951. Many generalizations appeared since then. Finding less and less restrictive sufficient conditions

\footnotetext{
${ }^{6}$ In this paper the a sequence of initial contract vector $(\mathrm{CV})$ is defined by optimization methods searching for equilibrium.

${ }^{7}$ The deviation is a sum of non-convex functions. It is well known that in this case the sum is not unimodal as usual.
} 
have been an active field of research (Forgo et al., 1999). The proofs of these conditions are based on the various fixed point theorems (Brouwer, 1912; Kakutani, 1941; Browder, 1968). Considering the examples of this book, we prefer simple existence conditions to the general ones. Testing the existence conditions, we express them in terms of the profit functions $u$ instead of the operators $T$.

For example, the equilibrium exists, if the profit $u(z)$ is strictly convex function of all the components of its parameters $z \subset Z$, and $Z$ is a convex set (Michael, 1976). In such cases, small changes of $z$ components will not change the maximum points considerably.

The situation would be different in the non-strictly-convex cases. Here even very small change of some parameters $z$, may change the maximum point $z^{*}$ of $u(z)$ considerably. For example, in linear cases this point may jump from minimal to maximal limits. In multi-modal cases the point $z^{*}$ can jump from one local minimum to another one. These sharp changes violate the continuity of the transformation $T$. The continuity of $T$ is needed in the Brouwer's fixed point theorem (Brouwer, 1912). In other theorems, such as Kakutani's (Kakutani, 1941) or Browder's (Browder, 1968), the fixed-point conditions are less restrictive. However, testing these conditions is not a trivial task.

\section{Search for Nash Equilibrium}

We may obtain the Nash equilibrium directly by simple iterations (22), if the transformation $T$ is contracting (von Neumann and Morgenstern, 1953). There are more sophisticated and efficient iterative procedures (Herings, 1994).

If the equilibrium exists but the transformation $T$ is not contracting then one minimizes the deviation.

The equilibrium is achieved, if the minimum

$$
\min _{z \in B}\|z-T(z)\|
$$

is zero. If the minimum (16) is positive then the equilibrium does not exist. That is a theoretical conclusion. In numerical calculations involving statistical modeling, some deviations are inevitable. Therefore, we assume that the equilibrium exists, if the minimum is not greater then modeling errors.

One can minimize deviation (16) by the usual stochastic approximation techniques (Ermoljev and Wets, 1988), if the deviation (16) is an unimodal function of $z$. If not, then the techniques of global stochastic optimization (Mockus, 1989) should be used. The global stochastic optimization may outperform the local one in the unimodal case, too. That happens, if the noise level is great because the Bayesian global stochastic optimization methods are less sensitive to large noise levels.

The norm $\|z-T(z)\|$ is not convenient for numerical optimization. Square of norm is better in this respect

$$
\min _{z \in B}\|z-T(z)\|^{2} .
$$


The same result one obtains by the following condition.

$$
\min _{z \in B} \sum_{i}\left(u_{i}(T(z))-u_{i}(z)\right)
$$

Here the difference $u_{i}(T(z))-u_{i}(z)$ shows the profit obtained by $i$ th server by breaking the contract $z$. We call the sum (18) as a fraud profit. Minimization of the fraud profit seems natural in economical terms and is convenient for computations. In these terms equilibrium means such a contract where fraud is not profitable.

\section{Contract Vector}

There are several possibilities to define the contract vector $z_{i}$. The first one is to include all three parameters: $z_{i}=\left(x_{i}^{0}, y_{i}^{0}, p_{i}^{0}, i=1, \ldots, m\right)$. Then the fraud-vector $\left(x_{i}^{1}, y_{i}^{1}, p_{i}^{1}\right.$, $i=1, \ldots, m)$ is obtained by maximizing the profits of each server $i$ assuming that all other partners $j \neq i$ will respect the contract $\left(x_{i}^{0}, y_{i}^{0}, p_{i}^{0}, i=1, \ldots, m\right)$

$$
\left(x_{i}^{1}, y_{i}^{1}, p_{i}^{1},\right)=\arg \max _{x_{i}, y_{i}, p_{i}} u_{i}\left(x_{i}, y_{i}, p_{i}, x_{j}^{0}, y_{j}^{0}, p_{j}^{0}, j=1, \ldots, m, j \neq i\right) .
$$

Here the profit function $u_{i}\left(x_{i}, y_{i}, p_{i}, x_{j}^{0}, y_{j}^{0}, p_{j}^{0}, j=1, \ldots, m, j \neq i\right)$ is defined by expression (4). There are rectangular constraints (13). A server $i$ optimizes only components $x_{i j}, i \neq j$ because $x_{i i}$ is defined by the balance condition $x_{i i}=b_{i}-\sum_{j \neq i} x_{j i}$.

In the two-server case

$$
\left(x_{12}^{1}, y_{1}^{1}, p_{1}^{1},\right)=\arg \max _{x_{12}, y_{1}, p_{1}} u_{1}\left(x_{12}, y_{1}, p_{1}, x_{21}^{0}, y_{2}^{0}, p_{2}^{0}\right),
$$

and

$$
\left(x_{21}^{1}, y_{2}^{1}, p_{2}^{1},\right)=\arg \max _{x_{21}, y_{2}, p_{2}} u_{2}\left(x_{21}, y_{2}, p_{2}, x_{12}^{0}, y_{1}^{0}, p_{1}^{0}\right)
$$

Condition (19) transforms vectors $z^{n}, n=0,1,2, \ldots$ into vectors $z^{n+1}$, where $z^{n}=$ $\left(x^{n}, y^{n}, p^{n}\right), x^{n}=\left(x_{1}^{n}, \ldots, x_{m}^{n}\right), y^{n}=\left(y_{1}^{n}, \ldots, y_{m}^{n}\right)$, and $p^{n}=\left(p_{1}^{n}, \ldots, p_{m}^{n}\right)$. Denote this transformation by $T$

$$
z^{n+1}=T\left(z^{n}\right), \quad n=0,1,2, \ldots
$$

Here the vector $z=\left(x_{i}, y_{i}, p_{i}, v_{i} i=1, \ldots, m\right) \in B \subset R^{m^{2}+2 m}$. We reach the equilibrium $^{8}$ at the fixed point $z^{n}$, where

$$
z^{n}=T\left(z^{n}\right)
$$

\footnotetext{
${ }^{8}$ If the equilibrium exists.
} 
The constraints (13) limits the Walras model. Therefore, setting these constraints one should resolve the following contradiction. Wider limits means more computing for optimization but less restriction for the Walras model, and vice versa. A way to get around this contradiction is to start with narrow bounds (13). One widens them if some of these bounds obviously restrict the profit maximum.

If the equilibrium test (16) fails additional testing of the sufficient existence conditions is needed. It is well known, that the equilibrium exists, if the profit $u$ is strictly convex function of parameters $(y, x, p)$ (Michael, 1976). Therefore, the "non-strict-convexity" of this function could be a reason of the failure to obtain the equilibrium.

Expressions (4) and (10) show that profits $u_{i}$ are linear functions of resource prices $p_{i}$. Linear functions are not strictly convex. For example, if this function is nearly constant then a small change of some parameters may switch the optimal resource price $p_{i}$ from zero to upper limit or vice versa.

Thus the Nash equilibrium may not exist in this case. Besides this model is not practical because the obligation to buy a fixed amount of resources regardless of the price in not the realistic one.

To avoid this difficulty "Look-Ahead" (LA) equilibrium models are considered. In the LA models the control parameters $p, y, x$ are divided into two groups: contract and free. For example in the model (19) all the parameters were included into the contract. The parameters that are not included into the contract are called as free. The natural example of the free parameter is resource consumptions $x$.

The important problem of models with free parameters is than one must anticipate the free parameters of all competitors.

We consider estimations of free parameters based on two different assumptions: Nash (NLA) and Greedy (GLA). In the Nash ( NLA) case we assume that all the servers select the free parameters at given contract parameters by conditions of the Nash equilibrium. In the Greedy (GLA) case servers select such free parameters that maximize their profits at fixed contract parameters. The NLA models may provide genuine Nash equilibrium if servers estimate competitors profit functions well enough. However GLA models may represent the behavior of managers better.

Look Ahead LA versions differs by the number of parameters to be set free. Denote by $\mathrm{LA}(\mathrm{p}, \mathrm{y})$ the case when only the vector of resource demand $x$ is free.

\section{7. "Nash-Look-Ahead" (NLA) Equilibrium}

\subsection{Profit Function}

Using NLA(p,y) the profit of the $i$ th server:

$$
U_{i}(p, y)=u_{i}\left(x_{j}^{*} y_{j}, p_{j}, j=1, \ldots, m\right)=a_{i} y_{i}^{*}+p_{i} \sum_{j \neq i} x_{i j}^{*}-\sum_{j \neq i} p_{j} x_{i j}^{*}
$$


Here $i$ is the server index. $a_{i}$ is the rate of customers. $x_{j}^{*}=\left(x_{j k}^{*}, k=1, \ldots, m\right), x_{j k}^{*}=$ $x_{j k}(p, y)$ is the equilibrium resource vector that defines the capacity $w_{j}$ of server $j$. All depend on prices $p$ and $y$. From the balance condition follows $x_{i i}^{*}=b_{i}-\sum_{j \neq i} x_{j i}^{*}$.

The vector $x^{*}$ is defined at fixed prices $(p, y)$ by this condition

$$
\min _{x \in B} \sum_{i}\left(u_{i}(T(x))-u_{i}(x)\right) .
$$

where $T(x)$ is the Nash transformation (15) of the vector $x$. Denote Nash equilibrium at fixed price vector $(p, y)$ as

$$
x^{*}=x(p, y) .
$$

In two-server cases

$$
U_{1}\left(p_{1}, y_{1}, p_{2}, y_{2}\right)=u_{1}\left(x_{12}^{*}, y_{1}, p_{1}, x_{21}^{*}, y_{2}, p_{2}\right)=a_{1} y_{1}+p_{1} x_{21}^{*}-p_{2} x_{12}^{*},
$$

and

$$
U_{2}\left(p_{1}, y_{1}, p_{2}, y_{2}\right)=u_{2}\left(x_{21}^{*}, y_{2}, p_{2}, x_{12}^{*}, y_{1}, p_{1}\right)=a_{2} y_{2}+p_{2} x_{12}^{*}-p_{1} x_{21}^{*}
$$

Here $x_{11}^{*}$ and $x_{22}^{*}$ are not included explicitly because they are defined by the balance conditions

$$
x_{11}^{*}=b_{1}-x+21^{*}, \quad x_{22}^{*}=b_{2}-x_{12}^{*} .
$$

One solves (25) many times for each fixed price vector $(p, y)$ before the equilibrium values $p=\left(p^{*}, y^{*}\right)$ are reached.

\section{2. $N L A(p, y)$ Equilibrium}

First a contract-vector $\left(p_{i}^{0}, y_{i}^{0} i=1, \ldots, m\right)$ is fixed. Then the fraud-vector $\left(p_{i}^{1}, y_{i}^{1} i=\right.$ $1, \ldots, m)$ is obtained by maximizing the profits of each server $i$ assuming that other partners $j \neq i$ keep the contract resource prices.

$$
\left(p_{i}^{1}, y_{i}^{1}\right)=\arg \max _{p_{i}, y_{i}} U_{i}\left(p_{i}, y_{i} p_{j}^{0}, y_{j}^{0} j=1, \ldots, m, j \neq i\right), \quad i=1, \ldots, m
$$

Here $p_{j}^{0}, y_{j}^{0} j \neq i$ are contact prices of competing servers $j \neq i$.

Condition (30) transforms vectors $p^{n}, y^{n} n=0,1,2, \ldots$ into vectors $p^{n+1}, y^{n+1}$, where $p^{n}=\left(p_{i}^{n}, i=1, \ldots, m\right)$, and $y^{n}=\left(y_{i}^{n}, i=1, \ldots m\right)$. Denote this transformation by $T$

$$
z^{n+1}=T\left(z^{n}\right), \quad n=0,1,2, \ldots
$$


where $z=(p, y)$. We reach the equilibrium ${ }^{9}$ at the fixed point $p^{n}$, where

$$
z^{n}=T\left(z^{n}\right)
$$

If the equilibrium exists but the transformation $T$ is not contracting then we minimize the square deviation

$$
\min _{z \in B}\|z-T(z)\|^{2}
$$

The equilibrium is achieved, if the minimum (33) is zero.

The alternative way to achieve equilibrium is by minimizing the fraud profit

$$
\min _{z \in B} \sum_{i}\left(U_{i}(T(z))-U_{i}(z)\right)
$$

Here the difference $U_{i}(T(z))-u_{i}(z)$ shows the profit obtained by $i$ th server by deviating from the NLA equilibrium $z^{*}$.

The final equilibrium values of $x^{*}$ are defined substituting $\left(p^{*}, y^{*}\right)$ into expression (26).

\section{3. $N L A(p, y)$ Algorithm}

\subsubsection{Reserve Resources}

Consider two-server case for simplicity. The capacity function (3) including reserves $x_{i j}^{r}$ :

$$
w_{i}=k_{i} \prod_{j=1}^{m}\left(1-\exp \left(-k_{i j}\left(x_{i j}\right)+x_{i j}^{r}\right)\right), \quad i=1.2,
$$

where $\sum_{i} x_{i j}^{r}<b_{j}, i, j=1,2$.

\subsubsection{Equilibrium Resources}

Assume, that at fixed prices $p_{i}, y_{i}, i=1,2$ servers obtain additional resources $x_{i j}$ following the Nash equilibrium conditions using this algorithm.

1. A pair $x_{12}^{0}, x_{21}^{0}$ is fixed.

2. Individual fraud profits $u^{1}$ and $v^{1}$ are calculated

$$
\begin{aligned}
& u^{1}=\max _{x_{12}} u\left(x_{12}, x_{21}^{0}\right), \\
& v^{1}=\max _{x_{21}} u\left(x_{12}^{0}, x_{21}\right) .
\end{aligned}
$$

3. General fraud profit is defined

$$
f^{1}=u^{1}-u^{0}+v^{1}-v^{0} .
$$

\footnotetext{
${ }^{9}$ If the equilibrium exists.
} 
4. The procedure is repeated for $K^{2}$ pairs $x_{12}, x_{21}$ defining a sequence of general fraud profits $f^{k}, k=1, \ldots, K^{2}$ where $K$ depends on fixed calculation error.

5. The pair $x_{1,2}, x_{21}$ with minimal fraud profit $f^{k}$ is considered as equilibrium.

\subsubsection{Equilibrium Prices}

1. A quadruple of prices $p_{1}^{0}, p_{2}^{0}, y_{1}^{0}, y_{2}^{0}$ is fixed.

2. Individual fraud profits $U^{1}, V^{1}$ and corresponding fraud prices $\left(p_{1}^{1}, y_{1}^{1}, p_{2}^{1}, y_{2}^{1}\right)$ are calculated

$$
\begin{aligned}
& U^{1}=\max _{p_{1}, y_{1}} U\left(p_{1}, y_{1}, p_{2}^{0}, y_{2}^{0}\right) \\
& \left(p_{1}^{1}, y_{1}^{1}\right)=\arg \max _{p_{1}, y_{1}} U\left(p_{1}, y_{1}, p_{2}^{0}, y_{2}^{0}\right)
\end{aligned}
$$

and

$$
\begin{aligned}
& V^{1}=\max _{p_{2}, y_{2}} U_{2}\left(p_{2}, y_{2} p_{2}^{0}, y_{2}^{0}\right) \\
& \left(p_{2}^{1}, y_{2}^{1}\right)=\arg \max _{p_{2}, y_{2}} U\left(p_{2}, y_{2} p_{2}^{0}, y_{2}^{0}\right) .
\end{aligned}
$$

3. General fraud profit is defined

$$
F^{1}=U^{1}-U^{0}+V^{1}-V^{0} .
$$

4. The procedure is repeated for a number $N$ pairs $x_{12}, x_{21}$ defining a sequence of general fraud profits $f^{k}, k=1, \ldots, N$ where $N$ is the number of iterations of optimization method/footnoteThe optimization of prices $p, y$ is performed by means of GMJ set of methods to make optimization as efficient as possible.

5. The quadruple $p_{1}^{*}, p_{2}^{*}, y_{1}^{*}, y_{2}^{*}$ with minimal fraud profit $f^{*}$ is considered as equilibrium.

\subsection{Profit Analysis}

The sufficient condition of equilibrium is convexity of profit functions. That is tested this way:

1. Fix the equilibrium prices $p_{1}^{*}, p_{2}^{*}, y_{1}^{*}, y_{2}^{*}$.

2. Change the first parameter $p_{1}$ step-by-step while keeping other three constant, draw two graphs $U\left(p_{1}, p_{2}^{*}, y_{1}^{*}, y_{2}^{*}\right)$ and $V\left(p_{1}, p_{2}^{*}, y_{1}^{*}, y_{2}^{*}\right.$, write values to tables.

3. Do the same for all the parameters $p_{1}, p_{2}, y_{1}, y_{2}$.

\subsection{Modelling Customers}

Intervals between customer arrivals are random and are defined by exponential distribution. The algorithm is described in Section 9

Initial testing the software could be more convenient by using regular arrivals of customers by equal intervals. 


\section{8. "Greedy-Look-Ahead" (GLA) Equilibrium}

Definition of GLA equilibrium is similar to that of NLA because in both the cases competitors responses. are anticipated while searching for the equilibrium prices. The difference is that the "greedy" servers select the free parameters not by equilibrium conditions but by maximal profit. We consider only one version GLA(p,y) where the free parameter is a vector of resource consumption $x$. The resource vector $x$ is predicted for all servers assuming that each server defines resource demand by maximizing profit at fixed both the resource and service price vectors $p$ and $y$.

Using GLA(p,y) one transforms linear profit functions of $p_{j}{ }^{10}$ into nonlinear ones. This way one may satisfy the necessary equilibrium conditions if the profit functions are convex. That is true in both the cases: NLA and GLA. In this sense both versions are equivalent. Thus one may select a version that better describes the actual economical behavior of participants.

Both the NLA and the GLA approaches is based on the important tacit assumption that servers know profit functions of their competitors. This is not true as usual. However, that is a price one pays for making profit functions strictly convex. This is needed to satisfy necessary equilibrium conditions. The price is not so great when servers know at least some approximation of competitors profit functions and their behavior

\subsection{Profit Function}

Using GLA(p,y) the profit of the $i$ th server:

$$
U_{i}(p, y)=u_{i}\left(x_{j}^{*} y_{j}, p_{j}, j=1, \ldots, m\right)=a_{i} y_{i}^{*}+p_{i} \sum_{j \neq i} x_{i j}^{*}-\sum_{j \neq i} p_{j} x_{i j}^{*}
$$

Here $i$ is the server index. $a_{i}$ is the rate of customers. $x_{j}^{*}=\left(x_{j k}^{*}, k=1, \ldots, m\right), x_{j k}^{*}=$ $x_{j k}(p, y)$ is the greedy resource vector that defines the capacity $w_{j}$ of server $j$ and is obtained by maximizing the profit function $U_{i}$ at given contract prices $p$ and $y$. From the balance condition follows $x_{i i}^{*}=b_{i}-\sum_{j \neq i} x_{j i}^{*}$. At fixed prices $(p, y)$ the vector $x^{*}$ is defined by these conditions

$$
\max _{x_{i j} \in B} U_{i}(p, y), \quad i=1, \ldots, m, i \neq j
$$

Denote the Greedy resource consumption vector at fixed price vectors $(p, y)$ as

$$
x^{*}=x(p, y) .
$$

In two-server cases

$$
U_{1}\left(p_{1}, y_{1}, p_{2}, y_{2}\right)=u_{1}\left(x_{12}^{*}, y_{1}, p_{1}, x_{21}^{*}, y_{2}, p_{2}\right)=a_{1} y_{1}+p_{1} x_{21}^{*}-p_{2} x_{12}^{*},
$$

\footnotetext{
${ }^{10}$ As defined by expressions (4) and (10).
} 
and

$$
U_{2}\left(p_{1}, y_{1}, p_{2}, y_{2}\right)=u_{2}\left(x_{21}^{*}, y_{2}, p_{2}, x_{12}^{*}, y_{1}, p_{1}\right)=a_{2} y_{2}+p_{2} x_{12}^{*}-p_{1} x_{21}^{*}
$$

Here $x_{11}^{*}$ and $x_{22}^{*}$ are not included explicitly because they are defined by the balance conditions

$$
x_{11}^{*}=b_{1}-x_{21}^{*}, \quad x_{22}^{*}=b_{2}-x_{12}^{*} .
$$

One solves (18) many times for each fixed price vector $(p, y)$ before the equilibrium values $p=\left(p^{*}, y^{*}\right)$ are reached.

\section{2. $G L A(p, y)$ Profit}

First a contract-vector $\left(p_{i}^{0}, y_{i}^{0} i=1, \ldots, m\right)$ is fixed. Then the fraud-vector $\left(p_{i}^{1}, y_{i}^{1} i=\right.$ $1, \ldots, m)$ is obtained by maximizing the profits of each server $i$ assuming that other partners $j \neq i$ keep the contract resource prices.

$$
\left(p_{i}^{1}, y_{i}^{1}\right)=\arg \max _{p_{i}, y_{i}} U_{i}\left(p_{i}, y_{i} p_{j}^{0}, y_{j}^{0} j=1, \ldots, m, j \neq i\right), \quad i=1, \ldots, m .
$$

Here $p_{j}^{0}, y_{j}^{0} j \neq i$ are contact prices of competing servers $j \neq i$.

In the two-server case

$$
\left(p_{1}^{1}, y_{1}^{1}\right)=\arg \max _{p_{1}, y_{1}} U_{1}\left(p_{1}, y_{1}, p_{2}^{0}, y_{2}^{0}\right)
$$

and

$$
\left(p_{2}^{1}, y_{2}^{1}\right)=\underset{p_{2}, y_{2}}{\arg \max } U_{2}\left(p_{2}, y_{2} p_{2}^{0}, y_{2}^{0}\right)
$$

Condition (52) transforms vectors $p^{n}, y^{n} n=0,1,2, \ldots$ into vectors $p^{n+1}, y^{n+1}$, where $p^{n}=\left(p_{i}^{n}, i=1, \ldots, m\right)$, and $y^{n}=\left(y_{i}^{n}, i=1, \ldots m\right)$. Denote this transformation by $T$

$$
z^{n+1}=T\left(z^{n}\right), \quad n=0,1,2, \ldots
$$

where $z=(p, y)$. We reach the equilibrium ${ }^{11}$ at the fixed point $p^{n}$, where

$$
z^{n}=T\left(z^{n}\right)
$$

If the equilibrium exists but the transformation $T$ is not contracting then we minimize the square deviation

$$
\min _{z \in B}\|z-T(z)\|^{2}
$$

\footnotetext{
${ }^{11}$ If the equilibrium exists.
} 
The equilibrium is achieved, if the minimum (33) is zero.

The alternative way to achieve equilibrium is by minimizing the fraud profit

$$
\min _{z \in B} \sum_{i}\left(U_{i}(T(z))-U_{i}(z)\right) .
$$

Here the difference $U_{i}(T(z))-u_{i}(z)$ shows the profit obtained by $i$ th server by deviating from the NLA equilibrium $z^{*}$.

The final equilibrium values of $x^{*}$ are defined substituting $\left(p^{*}, y^{*}\right)$ into expression (26).

\section{Monte-Carlo Simulation}

\subsection{Search for Equilibrium}

The analytical solution of the described market models is not practical. Therefore, we briefly consider the basic steps of an algorithm of the statistical simulation using MonteCarlo techniques. The algorithm implements two basic tasks:

- generates the next event time $t$,

- updates the state of queuing system defined by the vector of waiting customers $n(t)=\left(n_{i}(t), i=1, \ldots, m\right)$,

- updates the vector $h(t)=\left(h_{i}(t), i=1, \ldots, m\right)$ of the service cost including the money charged and the time lost.

There are $2 m+2$ types of event times $t$ :

- the time $t$ when a customer arrives into the system,

- the time $t$ when a customer arrives into the $i$ th server, $i=1, \ldots, m$,

- the time $t$ when a customer departs from the $i$ th server,

- the time $t$ when a customer abandons the service (departs from the system without being served).

Here $i=1, \ldots, m$. The system state is updated at each event time $t$. Two vectors define the system state:

- a vector $n=n(t)$ with $m$ components $n=\left(n_{1}, \ldots, n_{m}\right)$, where $n_{i}=n_{i}(t)$ shows the number of customers waiting for the service of the $i$ th server,

- a vector $h=h(t)$ with $m$ components $h=\left(h_{1}, \ldots, h_{m}\right)$, where $h_{i}(t)=y_{i}+$ $\gamma_{i}, \gamma_{i}=n_{i}(t) / w_{i}$ shows the total customer expenses, $y_{i}$ is money charged for the service, and $\gamma_{i}$ is the time lost waiting for the service of the $i$ th server ${ }^{12}$.

There are no state changes between events. The basic steps of the Monte Carlo algorithm:

1. Fix the zero event time $t=t^{0}=0$ when the first customer arrives.

\footnotetext{
${ }^{12}$ For simplicity, it is assumed that "time-is-money" and that a unit of time cost a unit of money, in the real life cases the corresponding coefficients should be included
} 
2. Define the zero state vector $n^{0}$ by the condition: $n_{i}^{0}=0, i=1, \ldots, m$ and the zero state vector $h^{0}$ by the condition : $h_{i}^{0}=y_{i}=0, i=1, \ldots, m$ because there are no customers waiting for service yet.

3. Define the next arrival into the system by the expression

$$
\tau_{a}=-1 / a \ln (1-\eta)
$$

where $\eta$ is a random number uniformly distributed in the interval $[0,1]$.

4. Chose the best server $i^{0}$ for the first customer by the condition $i^{0}=\arg \min _{i=0, \ldots, m} h_{i}$ where $h_{i}=y_{i}$, because $\gamma_{i}=0, i=1, \ldots, m$ since there are no customers waiting yet, $i^{0}=0$ means that the customer abandons the service.

5. Define the time of event when the first customer will be served by the server $i^{0}$ using the expression

$$
\tau_{i^{0}}=-1 / x_{i^{0}} \ln (1-\eta) .
$$

6. Define the next event $t^{1}$ by comparing the arrival time $\tau_{a}$ and the service time $\tau_{i^{0}}$ : if $\tau_{a}<\tau_{i^{0}}$ then $t^{1}=\tau_{a}$, if $\tau_{a}>\tau_{i^{0}}$ then $t^{1}=\tau_{i^{0}}$,

7. Define the system state at the next event $t^{1}$ :

$$
\begin{aligned}
& \text { if } t^{1}=\tau_{a} \text { then } n_{i^{0}}=1 \text { and } n_{i}=0, i=1, \ldots, m, i \neq i^{0}, \\
& \text { consequently } h_{i^{0}}=y_{i^{0}}+1 / w_{i^{0}} \text { and } h_{i}=y_{i}, i=1, \ldots, m, i \neq i^{0}, \\
& \text { if } t^{1}=\tau_{i^{0}} \text { then } n_{i}=0, i=1, \ldots, m \text {, and } h_{i}=y_{i}, i=1, \ldots, m, i \neq i^{0} .
\end{aligned}
$$

Definition of later events and system states is longer but the main idea remains the same. For illustration, we update the fourth step for the $n$th customer:

- chose the best server $i^{0}$ for the $n$th customer by the condition $i^{0}=\arg \min _{i=0, \ldots, m} h_{i}$, where $h_{i}=y_{i}+\gamma_{i}, \gamma_{i}{ }^{0}=n_{i} / \omega_{i^{0}}$, and $n_{i}$ is the number of customers waiting for server $i$.

The algorithm can be directly adapted to the Monte-Carlo simulation of the Nash model with two servers, too. For example, that can be done this way:

- set to unit both the resource charges $p_{i}=1, i=1,2$,

- set to zero resources exchanges $x_{21}=x_{12}=0$,

- assume that $x_{11}=x_{1}, x_{22}=x_{2}$, where variables $x_{1}, x_{2}$ are from expression (59).

$$
u_{i}=u_{i}\left(x_{1}, y_{1}, \ldots, x_{m}, y_{m}\right)=a_{i} y_{i}-x_{i}, \quad i=1, \ldots, m
$$

where $u_{i}$ is the profit, $y_{i}$ is the service price, $a_{i}$ is the rate of customers, $x_{i}$ is the running cost, and $i$ is the server index. Assume that a server capacity $w_{i}$ is an increasing function of the running cost $x_{i}$ :

$$
w_{i}=\phi_{i}\left(x_{i}\right) .
$$

If the number of severs $m>2$ then some modification of the described algorithm is needed. 


\subsection{Testing Equilibrium Conditions}

In the Monte-Carlo simulation, equilibrium tests (17) should be relaxed by accepting some simulation error $\epsilon$ :

$$
\min _{z \in B}\|z-T(z)\|^{2} \leqslant \epsilon
$$

or

$$
\min _{z \in B} \sum_{i}\left(u_{i}(T(z))-u_{i}(z)\right) y \leqslant \epsilon
$$

To test the convexity of profit functions, some smoothing is desirable. The smoothing eliminates the random deviations due to Monte-Carlo simulation. Both the convolution and the Wiener filters are applied for smoothing the profit functions (possibly multimodal). The convolution filter defines the function at some fixed point as an average of values in the neighborhood of this point. The more sophisticated Wiener filter is implemented, too.

\subsection{Wiener Filter}

If the objective function $f(x)$ is defined by Monte Carlo simulation, some noise is present. That means that one observes the sum

$$
\phi(x)=f(x)+\xi
$$

where $\xi$ is a random number called the noise.

If finding the optimum of a convex function $f(x)$ is the only goal, we can apply some stochastic optimization algorithms (Ermoljev and Wets, 1988). These algorithms converge to the optimum of $f(x)$ by filtering the noise during the optimization process.

To test properties of $f(x)$, such as convexity, unimodality e.t.c., we need specific smoothing algorithms that eliminate false local optima. In one-dimensional cases, a convenient smoothing function is the conditional expectation of the Wiener process with noise (Kushner, 1964; Zilinskas and Senkiene, 1981). It is assumed that the optimization parameter $x \in[0,1]$, the Wiener parameter is a unit, and the noise $\xi$ is Gaussian with zero mean and variance $S_{i}$ at the points $x^{i} \in[0,1], i=1, \ldots, n$. Then the conditional expectation $\mu_{k}=\mu_{n}\left(x^{k}\right)$ of the objective function $y_{k}=f\left(x^{k}\right)$ at some fixed point $x^{k}$ with respect to the observations results $y_{i}=\phi\left(x^{i}\right), i=1, \ldots, n$, can be expressed this way

$$
\mu_{k}=\frac{\sum_{i=1}^{k} b_{i} y_{i}+\frac{b_{k}}{c_{k}} \sum_{i=k+1}^{n} c_{i} y_{i}}{\sum_{i=1}^{k} b_{i}+\frac{b_{k}}{c_{k}} \sum_{i=k+1}^{n} c_{i}} .
$$


Here

$$
\begin{aligned}
& b_{1}=1, \quad B_{1}=1 \text {, } \\
& b_{2}=\frac{S_{1}^{2}+r_{1,2}}{S_{2}^{2}}, \quad B_{2}=B_{1}+b_{2} \text {, } \\
& b_{k}=\frac{S_{k-1}^{2} b_{k-1}+r_{k, k-1} B_{k-1}}{S_{k}^{2}}, \quad B_{k}=B_{k-1}+b_{k}, \\
& c_{n}=0 \text {, } \\
& c_{k}=\frac{S_{k+1}^{2} c_{k+1}+r_{k, k+1} C_{k+1}}{S_{k}^{2}}, \quad C_{k+1}=\sum_{i=k+1}^{n} c_{i}, \\
& r_{i, j}=\left|x^{i}-x^{j}\right| \text {. }
\end{aligned}
$$

It is convenient to assume that

$$
S_{i}=S, \quad i=1, \ldots, n,
$$

where $S$ can be considered as a smoothing parameter.

If $S=0$ then no smoothing occurs. The smoothing function (the conditional expectation) is the piece-wise line connecting the observed points (see Fig. 1).

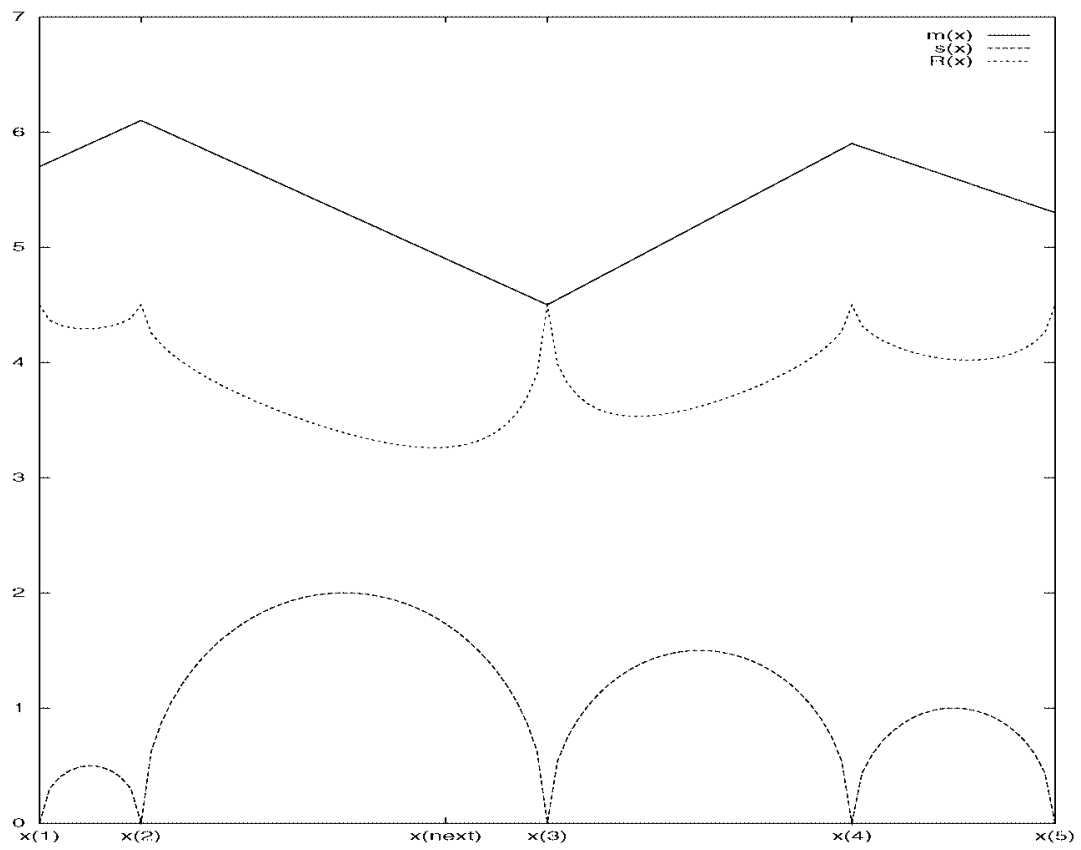

Fig. 1. The Wiener Model. The conditional expectation $m(x)$, the conditional standard $s(x)$, and the risk function $R(x)$ regarding fixed values $x(1), y(1), x(2), y(2), \ldots$ 
If $S$ is large then one obtains a horizontal line corresponding to the average value of observed values $y_{i}$. That means a sort of "total smoothing". Using the Wiener smoothing of a single realization one predicts average of multiple realizations if the underlying assumptions of the Wiener model are true.

Figs. 2 and 3 show how the first server profit $u_{1}$ depends on the price $p_{1}$ charged

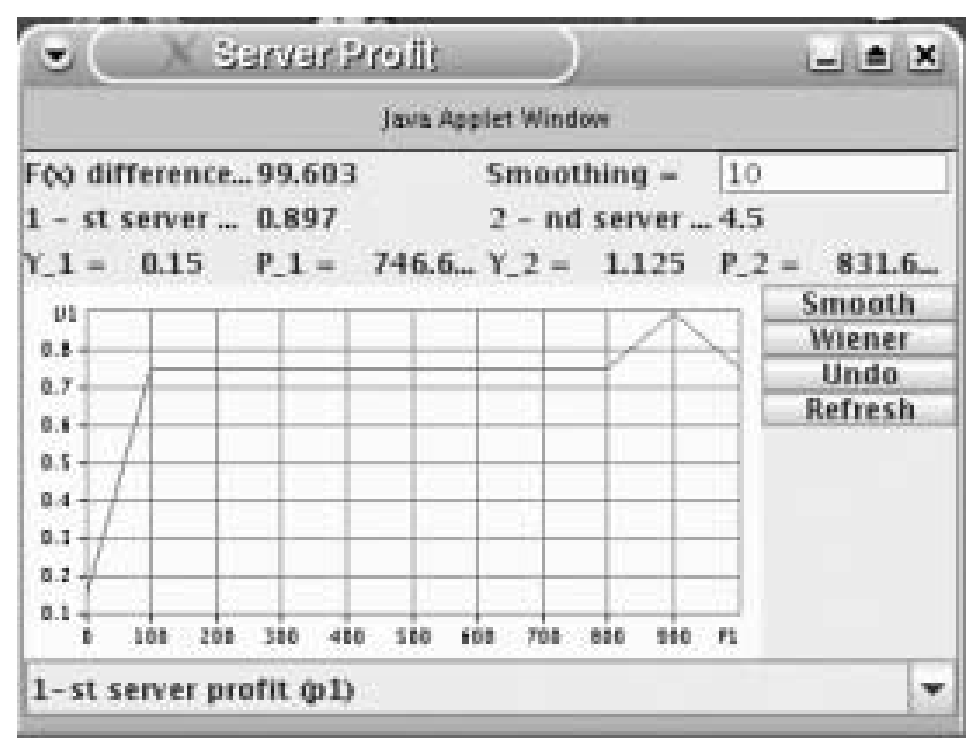

Fig. 2. The relation of the profit $u_{1}$ on the resource price $p_{1}$.

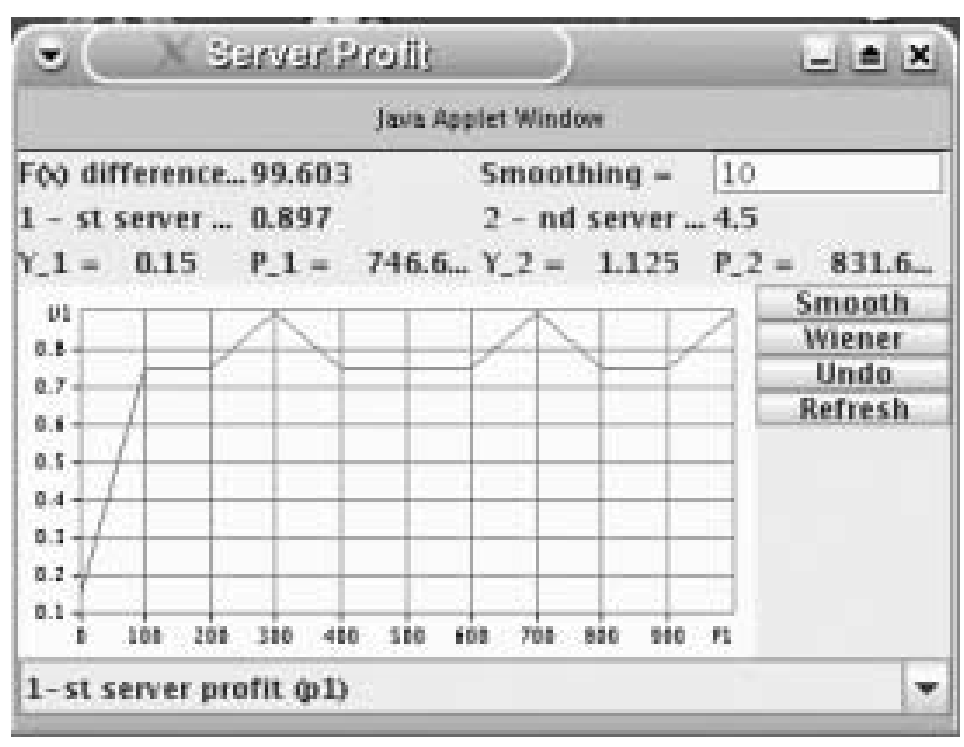

Fig. 3. The "refreshed" relation of the profit $u_{1}$ on the resource price $p_{1}$. 


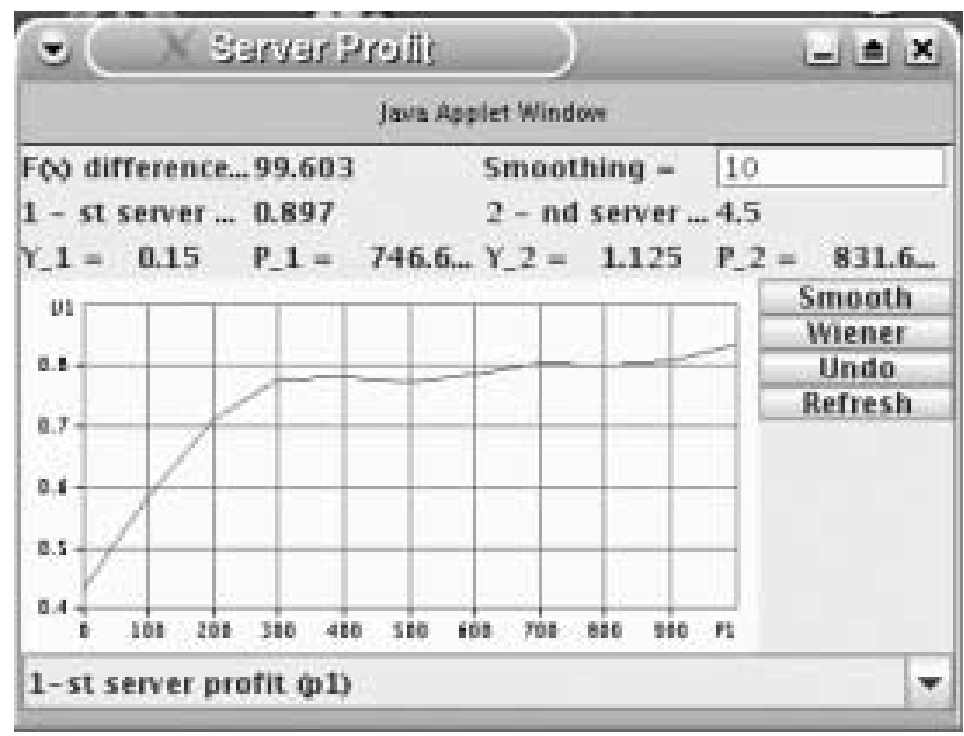

Fig. 4. The "refreshed" relation of the profit $u_{1}$ on the resource price $p_{1}$ smoothed by the Wiener filter.

for its resources. There are two samples of the same relation. They show the differences between two samples of random arrival times of hundred customers.

The buttons "smooth" and "wiener" on the right side are for switching on these filters. The button "smooth" is for the convolution filter. The button "wiener" is for the Wiener filter.

The field denoted by "S" at the top right corner, defines the smoothing parameter $S$ of the Wiener filter (see expression (71).

One can increase the level of smoothing by pressing the "smooth" or "wiener" buttons repeatedly.

The "refresh" button repeats the Monte-Carlo simulation of the same profit function.

Fig. 4 shows the sample of the "refreshed" graph smoothed by the Wiener filter.

The underlying profit function is the same in all the Figs. 2 and 3 defines different graphs because of the simulation errors. After smoothing 4 the level of these errors is lower.

Note that the actual screenshots are displayed instead of the traditional nice pictures made by presentation tools. The advantage of screenshots is that readers willing to test the model directly by uploading data will observe the results in exactly the same form.

\section{Software Implementation}

The software is intended to be a tool for graduate studies and scientific cooperation in the Internet environment. Thus the software should be platform independent. One must get the same results in the same form as other colleaques working on different computers 
and using different operating systems. Realization of the Walras model including the stochastic arrival times of customers is complicated and time consuming task.

Java j2sdk1.5 satisfies all that. The Java implementation of the Walras model by (Treigys, 2004) is on the web-sites.

\section{Graphical Users Interface}

\subsection{Input-Output}

The original Java optimization framework GMJ (Mockus, 1989) was used. Tis is an open system: various optimization methods could be included to test different models by some standard or user-defined graphical representation systems. For example, Figs. 3 and 4 were made by a custom-made system the "Profit Analysis", Figs. 10 and 11 were obtained by a standard GMJ analysis system the "Projection".

The Bayesian method "Bayes" (Mockus, 1989) was used for most of the examples. The coordinate method "Exkor" (Zilinskas, 1981) was applied to test the "globality" of the objective functions, see Figs. 10 and 11.

The input data of the Walras model:

- $B 1$ and $B 2$ are the stocks of server resources allocated for sale, both set to 1.0,

- $B 11, B 22, B 12$ and $B 21$ are the minimal stocks of resources needed for normal operation, all set to 0.1 ,

- the "run-away" threshold is $C 0$, set to 20 ,

- the customer rate is $A$, set to 100 ,

- the efficiency of servers $Z_{i j}$, all set to 1.0 ,

- the accuracy of equilibrium search and accuracy of profit analysis both are set to $10 \%$,

- Regularclient parameter is set to zero, that means random arrivals,

- the lower bounds of all the prices $p 1, p 2, y 1, y 2$ are set to zero,

- the upper limits of resource prices $p 1, p 2$ are set to 1000.0 ,

- the upper limits of service prices $y 1, y 2$ are 25.0,

- the default values ${ }^{13}$ are set in the middle.

The results of optimization:

- Iteration denotes the number of best iteration $F(x)$ means the minimal deviation from the equilibrium point,

- $p 1, p 2, y 1, y 2$ are the prices of resources and services obtained searching for equilibrium.

\subsection{Profit Analysis}

Figs. 5 and 6 show how the profits of servers depend on the service charges $y 1, y 2$.

Figs. 2 and 7 show how the profits of servers depend on the resource prices $p 1, p 2$.

\footnotetext{
${ }^{13}$ The default values are needed only for methods starting from some initial point, for example coordinate search by the Wiener model Exkor (Zilinskas, 1981).
} 


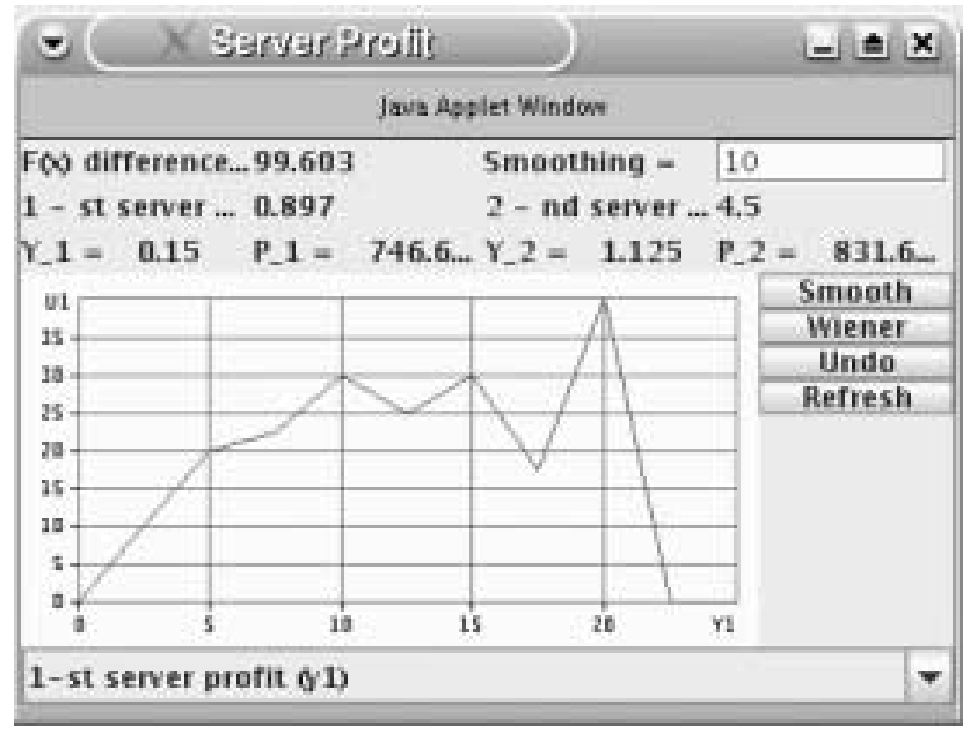

Fig. 5. The relation of profits on the service charge $y 1$.

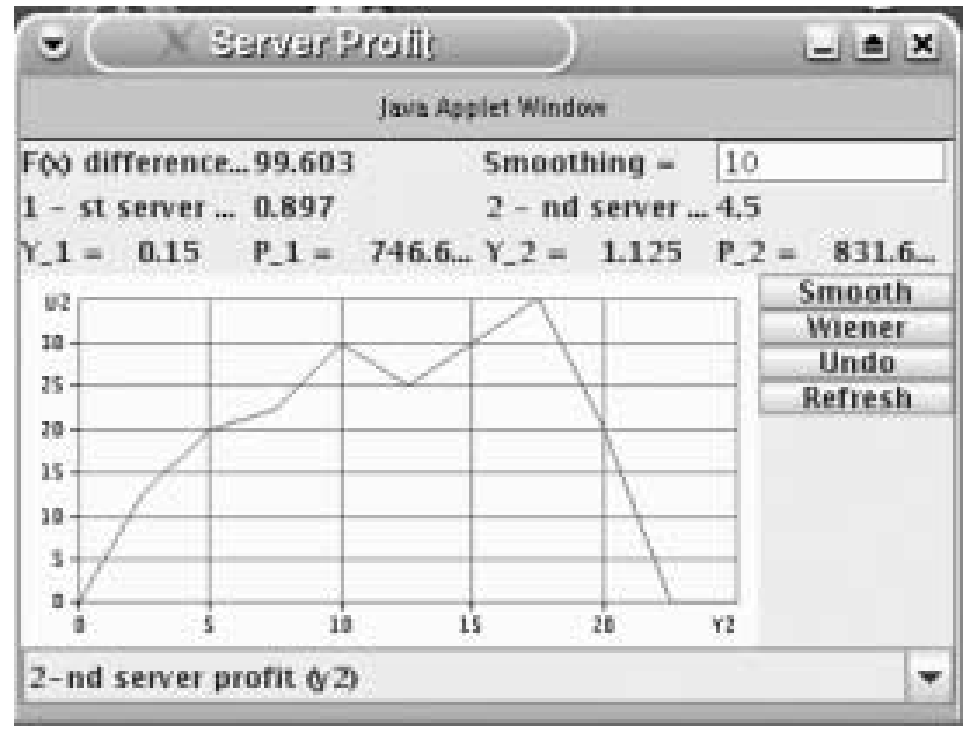

Fig. 6. The relation of profits on the service charge $y 2$.

\subsection{Globality Test}

To test globality of the objective function one needs regular clients and coordinate optimization algorithms where changing one variable all the others are fixed, for example Exkor by (Zilinskas, 1981). 


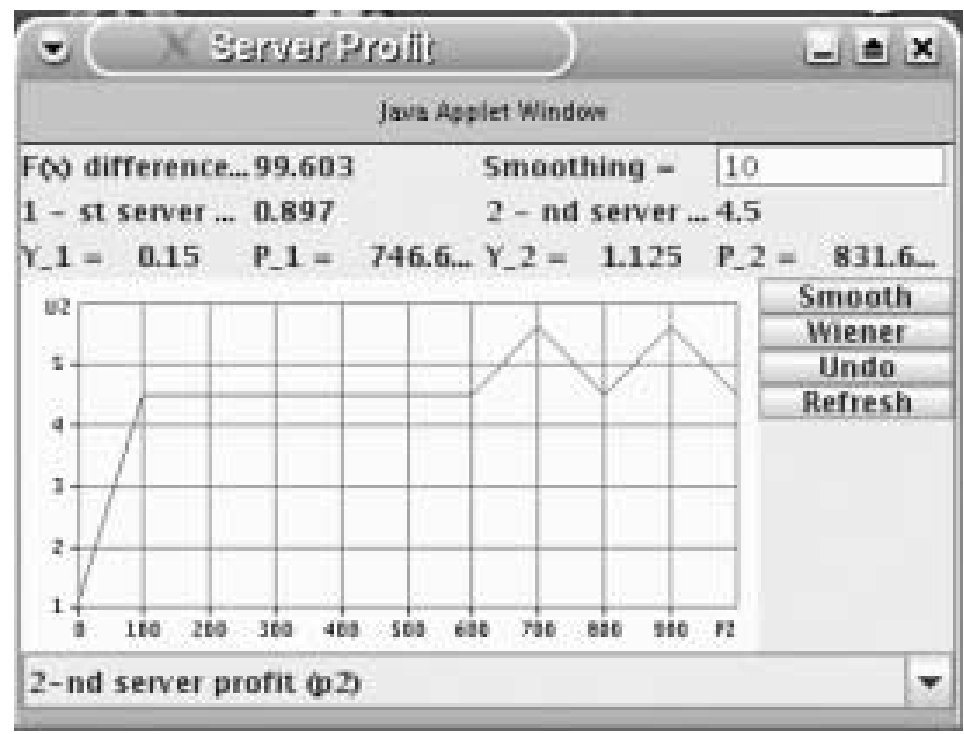

Fig. 7. The relation of profits on the resource price $p 2$.

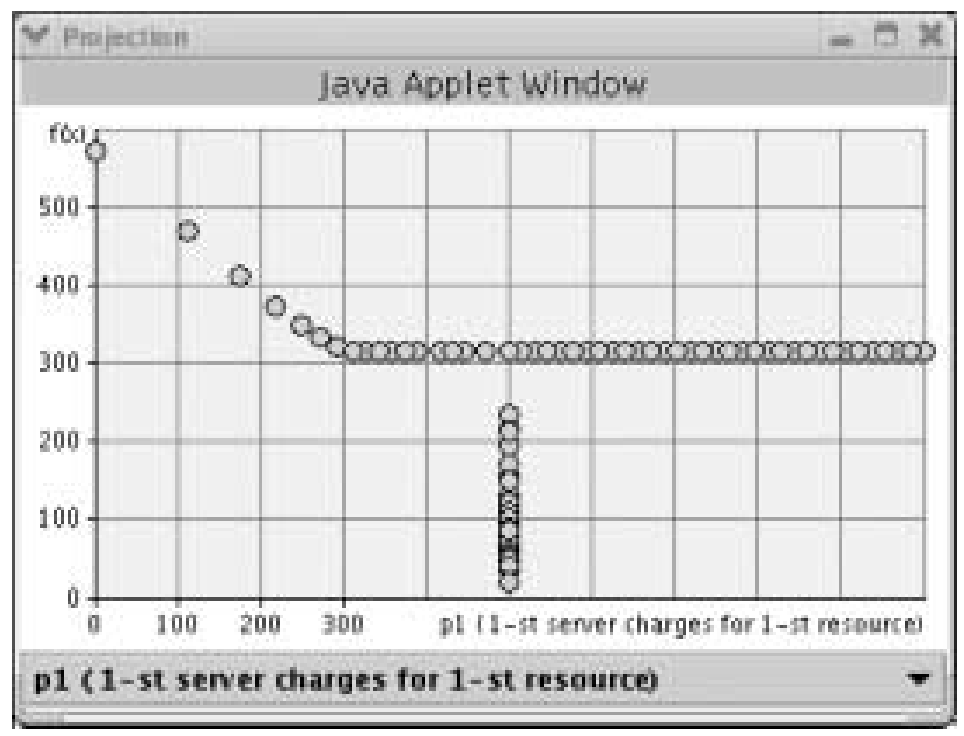

Fig. 8. Relation of the objective function on the resource price $p 1$.

Figs. 8 and 9 show how the objective function depends on the resource prices. In the given service price range the objective is nearly unimodal.

Figs. 10 and 11 show how the objective function depends on the service prices. Note that here the objective is multimodal, minimal values are at the ends of given service price interval. Thus global optimization methods are needed even in the simplest case of 


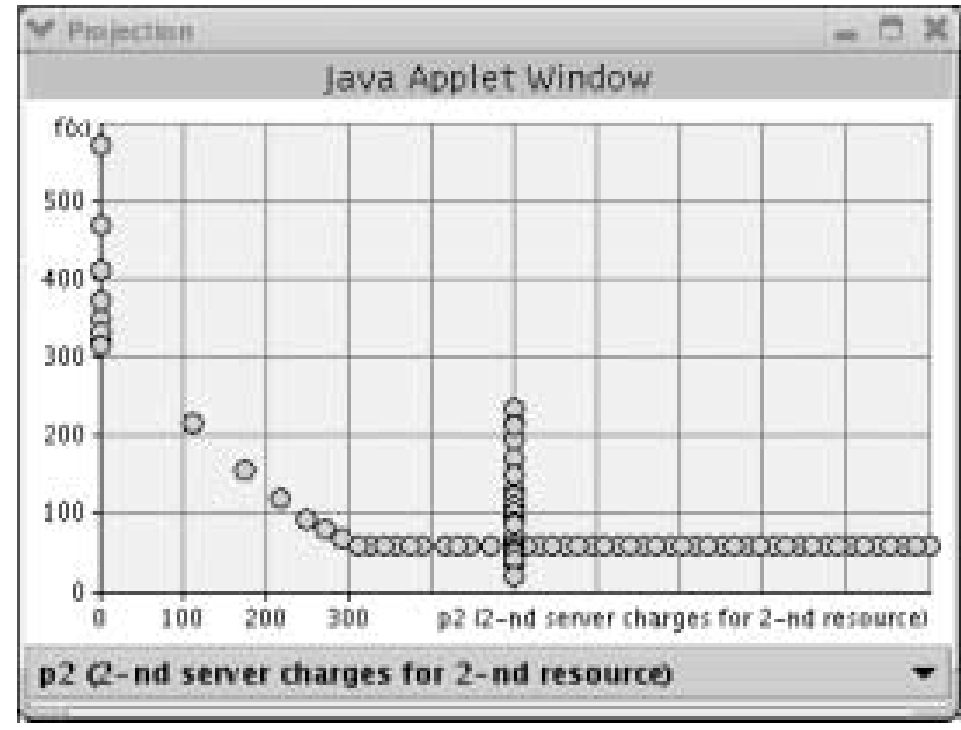

Fig. 9. The relation of the objective function depends on the resource price $p 2$.

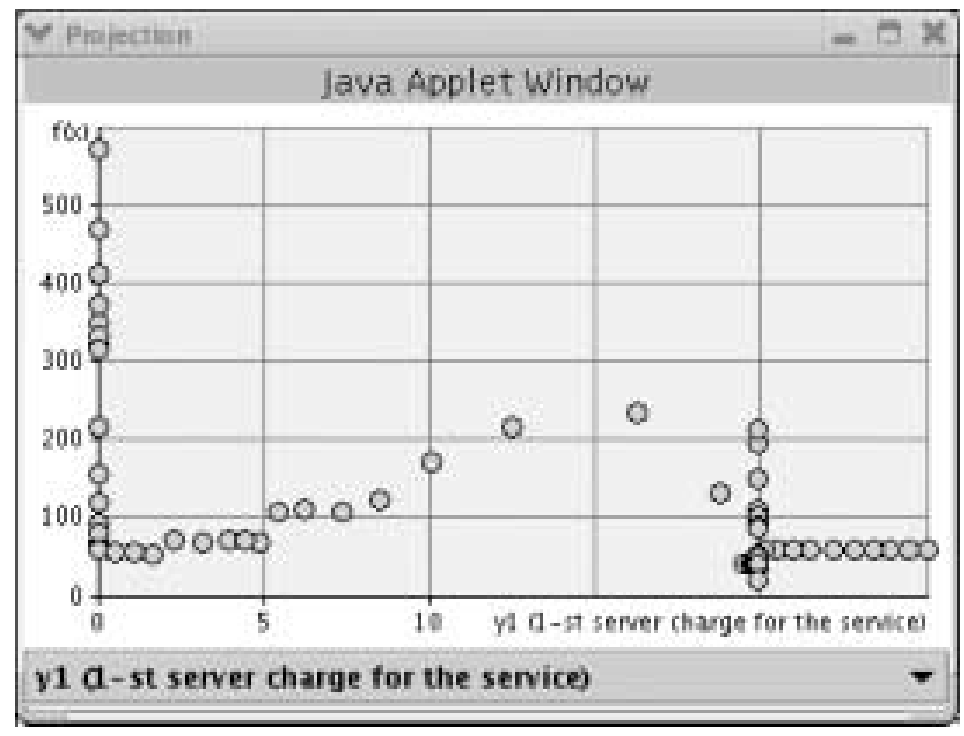

Fig. 10. Relation of the objective function on the service price $y 1$

regular customers. It is noticed (Mockus, 1997a; Mockus, 1997b) that Bayesian methods of global optimization could be more efficient as compared to local methods of stochastic optimization in cases of unimodal objective, too, if the "noise" level is sufficiently large. 


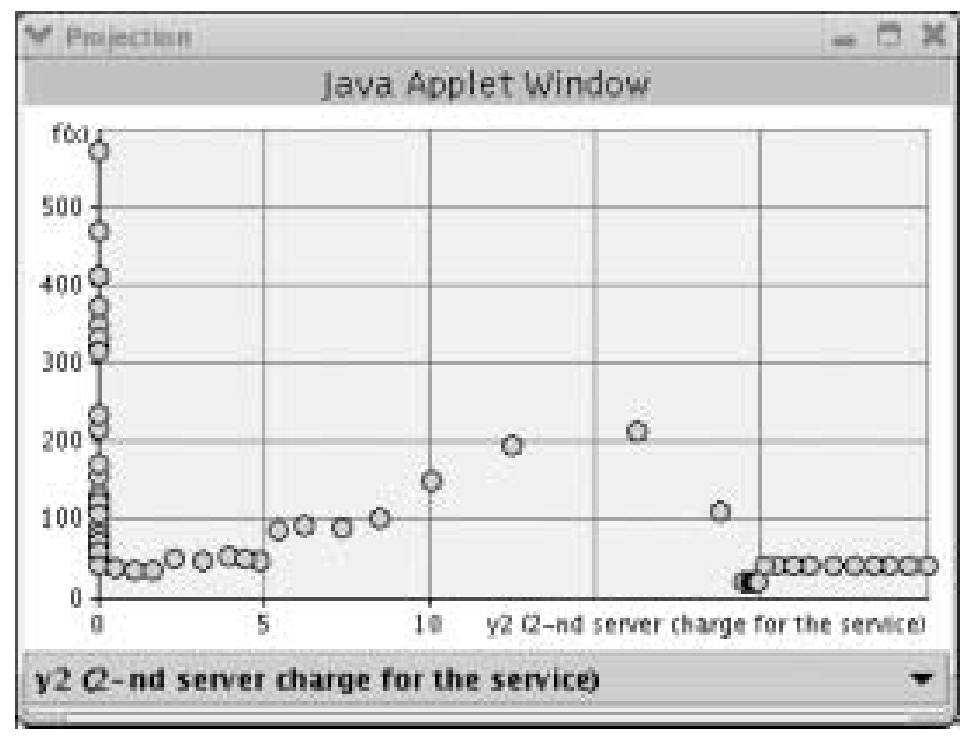

Fig. 11. Relation of the objective function on the service price $y 2$.

\subsection{Example of Local Optimization}

Some algorithms of local optimization can reach the exact solution if the starting point and other parameters are adapted to a fixed deterministic multimodal function.

After lengthy trials by the well known modification of the simplex algorithm Flexi (Himmelblau, 1972) some illustrative example was made.

The exact equilibrium $F(x)=0$ in the regular customers case was reached after 32 iterations.

That is special case. In the case of random customers and arbitrary starting point the results are rather poor, as expected.

\section{Conclusions}

The process of Walras model development shows that mathematical modelling and software implementation is iterative process. The main reason is that results depends on the accuracy of calculations. High accuracy often requires long computing time. Ressolving this contradiction one needs to adapt the theoretical models.

For example, the first version of the Walras model was implemented by (Perlibakas, 1999). The first update is described in (Treigys, 2003; Skruodys, 2004). The final software version was realized by (Treigys, 2004). Theoretical models were changed several times during this five years of development gradually adapting to the real computing environments. 


\section{References}

Brouwer, L. (1912). Uber abbildung von mannigfaltigkeiten. Math. Ann., 71, 97-115.

Browder, F. (1968). The fixed point theory of multivalued mappings in topological vector spaces. Math. Ann. 177, 283-302.

Ermoljev, Y., and R.-B. Wets (1988). Numerical Techniques for Stochastic Optimization. Springer-Verlag, Berlin-New York-London.

Forgo, F., J. Szep and F. Szidarovszky (1999). Introduction to the Theory of Games. Kluwer Academic Publishers.

Gnedenko, B., and I. Kovalenko (1987). Introduction to the Theory of Queuing. Nauka, Moscow (in Russian).

Herings, P. (1994). A gobally and universally stable price ajustment process. Technical Report 9452, Center for Economic Research, Tilburg University, The Netherlands, Tilburg.

Himmelblau (1972). Applied Nonlinear Programming. McGraw-Hill.

Kakutani, S. (1941). A generalization of brouwer's fixed point theorem. Duke Journal of Mathematics, 8 , 457-459.

Kushner, H. (1964). A versatile stochastic model of a function of unknown and varying form. J. of Mathematical Analysis and Applications, 5, 150-167.

Michael, J. (1976). The Computation of Fixed Points and Applications. Springer-Verlag, Berlin.

Mockus, J. (1989). Bayesian Approach to Global Optimization. Kluwer Academic Publishers, DordrechtLondon-Boston.

Mockus, J. (1997a). A set of examples of global and discrete optimization: application of bayesian heuristic approach i. Informatica, 8(2), 237-264.

Mockus, J. (1997b). A set of examples of global and discrete optimization: application of bayesian heuristic approach ii. Informatica, 8(4), 495-526.

Mockus, J. (2000). A Set of Examples of Global and Discrete Optimization: Application of Bayesian Heuristic Approach. Kluwer Academic Publishers.

Nash, J. (1950). Equilibrium points in $n$-person games. Proc. Nat. Acad. Sci. USA, 36, 48-49.

Nash, J. (1951). Noncooperative games. Annals of Mathematics, 54, 286-295.

Perlibakas, V. (1999). Software for the walras problem. Technical Report, Kaunas Technological University, Faculty of Informatics, Kaunas, Lithuania. (in Lithuanian).

Rolstadas, A. (1995). Enterprise modeling for competitive manufacturing. Control Engineering Practice, 3, 43-50.

Rosenmuller, J. (1981). The Theory of Games and Markets. North-Holand, Amsterdam.

Scarf, H., and T. Hansen (1973). The Computation of Economic Equilibria. Yale University Press, New HavenLondon.

Skruodys, N. (2004). Investigation of the Competition Models. PhD thesis, Kaunas Technological University, Kaunas, Lithuania

Sviderskaite, A. (2003). Software for the walras problem, walras profit analysis. Technical Report, Kaunas Technological University, Faculty of Informatics, Kaunas, Lithuania (in Lithuanian).

Treigys, P. (2003). Software for the walras problem. Technical Report, Vilnius Gedimino Technical University, Vilnius, Lithuania (in Lithuanian).

Treigys, P. (2004). Updated software for the walras problem. Technical Report, Vilnius Gedimino Technica University, Vilnius, Lithuania. (in Lithuanian).

von Neumann, J., and Morgenstern, O. (1953). Theory of Games and Economic Behaviour. Princeton University Press, Princeton, New Jersey.

Walras, L. (1874). Elements d'Economie Politique Pure. LKorbaz and Company, Lousanne.

Zilinskas, A. (1981). Two algorithms for one-dimansional multimodal minimization. Optimization, 12, 53-63.

Zilinskas, A., and Senkiene, E. (1981). On the convergence of one-stage algorithms for one-variable multimoda optimization in the presence of noise. Lithuanian Mathematical Journal, 21, 41-46. 
J. Mockus graduated Kaunas University of Technology, Lithuania, in 1952. He got his doctor habilitus degree in the Institute of Computers and Automation, Latvia, in $1967 . \mathrm{He}$ is a head of Optimal Decision Theory Department, Institute of Mathematics and Informatics, Vilnius, and professor of Kaunas University of Technology. His research interests include global and discrete optimization.

\section{Walraso konkurencinis modelis, globalaus optimizavimo pavyzdys}

\section{Jonas MOCKUS}

Walraso teorija yra gerai žinoma ir plačiai naudojama nagrinejjant rinkos ekonomikos procesus. Sukurti iteraciniai metodai pusiausvyrai rasti.

Straipsnyje pasiūlytas ir igyvendintas naujas požiūris, kai Walraso pusiausvyros ieškojimas formuluojamas kaip stochastinio globalaus optimizavimo uždavinys. Tokiu būdu įvertinamas atsitiktinis užsakymu pobūdis ir užtikrinamas konvergavimas į pusiausvyra, jei ji egzistuoja.

Walraso modelio programinè realizacija sudaro dalị integruotos distanciniu aukštujuju studiju ir mokslinio bendradarbiavimo sistemos optimizavimo bei lošimų ir rinkos teorijų srityse veikiančios interneto aplinkoje. Sistema suteikia mokslininkams galimybes konkrečiai ištirti, kaip efektyviai panaudoti optimizaciniu modelių programinę iranga.

Tikslas yra pateikti ịranki, palengvinantį mokslinį bendradarbiavimą bei stimuliuojantį kūrybinius jaunujų mokslininkų sugebejjimus.

Tinklapyje http ://soften.ktu.It/ mockus pateikiama teorija bei programinè realizacija Walraso bei eilès kitụ ekonominių ir finansinių modelių, nagrinejjant juos kaip bendros optimizavimo teorijos pavyzdžius. 